\title{
A new species of small-eared shrew in the Cryptotis thomasi species group from Costa Rica (Mammalia: Eulipotyphla: Soricidae)
}

\author{
Neal Woodman ${ }^{1} \cdot$ Robert M. Timm ${ }^{2}$
}

Received: 13 April 2016/Accepted: 1 August 2016/Published online: 27 August 2016

(C) Mammal Research Institute, Polish Academy of Sciences, Białowieża, Poland (outside the USA) 2016

\begin{abstract}
We describe a new species of small-eared shrew, genus Cryptotis Pomel, 1848 (Eulipotyphla: Soricidae), from near the community of Monteverde in the Tilarán highlands of northwestern Costa Rica. The new species is immediately distinguished from all other Costa Rican shrews its large size and long tail. Morphologically, it belongs to the Cryptotis thomasi group of small-eared shrews, a clade that is more typically distributed in the Andes Cordillera and other highland regions of northern South America. The new Costa Rican species and the Panamanian endemic Cryptotis endersi Setzer, 1950 are the only two members of this species group known to occur in Central America. Like most other members of the C. thomasi group for which the postcranial skeleton has been studied, the new species tends be more ambulatory (rather than semi-fossorial) when compared with other members of the genus. Our survey efforts over several decades failed to locate a population of the new species, and we discuss its conservation status in light of its limited potential distribution in the Tilarán highlands and the significant climatic change that has been documented in the Monteverde region during the past four decades.
\end{abstract}

Keywords Biodiversity - Central America . Cloud forest . Conservation $\cdot$ Morphology $\cdot$ Neotropics

Communicated by: Jan M. Wójcik

Neal Woodman

woodmann@si.edu

1 U.S. Geological Survey, Patuxent Wildlife Research Center, National Museum of Natural History, Smithsonian Institution, Washington, DC 20013-7012, USA

2 Department of Ecology and Evolutionary Biology, University of Kansas, Lawrence, KS 66045, USA

\section{Introduction}

Small-eared shrews of the genus Cryptotis have a wide distribution that extends from eastern North America through Central America to the northern Andean highlands of South America, with isolated populations in the Sierra de Aroa and Serranía Litoral of northern Venezuela (Quiroga-Carmona and Molinari 2012; Quiroga-Carmona 2013). The genus attains its greatest diversity in the northern tropics of southern Mexico and Central America, although overlap in the local distributions of species appears to be limited (Woodman et al. 2012). The southern Central American nation of Costa Rica is home to four recognized species of small-eared shrews. These species are partitioned among three of the five traditional, morphologically defined species groups (Choate 1970; Woodman and Timm 1993, 1999) that appear to be distinct phylogenetic clades within the genus (He et al. 2015): Cryptotis gracilis (Miller, 1911) of the Middle American Cryptotis goldmani group; Cryptotis merriami Choate, 1970 and Cryptotis nigrescens (Allen, 1895) of the Central American and Colombian C. nigrescens group; and Cryptotis orophilus (Allen, 1895) of the North American Cryptotis parvus group. Missing from Costa Rica are members of the more northern Cryptotis mexicanus group, which was originally thought to include the C. goldmani group (Woodman and Timm 1999), but is now restricted to Mexico (Guevara and Cervantes 2014; He et al. 2015). Also lacking from Costa Rica were members of the Cryptotis thomasi group that, with the exception of Cryptotis endersi Setzer, 1950 from the Chiriquí highlands of western Panama, was otherwise restricted to the northern Andes and similar highlands of northern South America (Woodman and Péfaur 2008; Quiroga-Carmona and Molinari 2012; Quiroga-Carmona 2013).

Herein, we describe a large, distinctive new species of small-eared shrew from the Monteverde Cloud Forest 
Reserve (Fig. 1) that extends the distribution of the $C$. thomasi group north to Costa Rica. The new species is only the second member of this mostly South American species group discovered north and west of the Darien Gap, and it represents the northernmost record for the group. This shrew is the first endemic mammal known from Monteverde. It increases the diversity of soricids identified from Costa Rica, which is now the only country known to contain members of the C. goldmani group, C. nigrescens group, C. parvus group, and $C$. thomasi group within its borders.

\section{Materials and methods}

In evaluating morphological variation among populations of Cryptotis, we used qualitative characters and quantitative variables from the skin, skull, and humerus. Terminology of dentition and dental characteristics follows Choate (1970). Anatomical terminology of the humerus follows Reed (1951). Capitalized life zone terminology follows Holdridge (1947). All measurements are in millimeters, and all weights are in grams. Skull measurements used in our analyses follow Woodman and Timm (1993) and were taken to the nearest $0.1 \mathrm{~mm}$ using either hand-held dial calipers or an ocular micrometer in a binocular microscope. Standard external measurements are those recorded by the collector, except for head-and-body length (HB), which we calculated by subtracting the recorded tail length (TL) from the total length. Abbreviations for external and skull measurements are explained in Table 1. Indices are expressed as percentages. Tabular summary statistics include mean \pm standard deviation (SD) and range. Unless otherwise specified, comparative characters in descriptions and diagnoses are expressed relative to those of up to 60 distinctive populations and species of Cryptotis. A character for a species is considered "small" if its mean is $>1$ SD below the mean for the genus, "medium" if it within $\pm 1 \mathrm{SD}$ of the genus mean, or "large" if greater than the genus mean by $>1$ SD.

We analyzed functionality of the humerus of the new species to assess degree of ambulatory versus fossorial locomotion using measurements and methods described in Woodman and Gaffney (2014) and Woodman and Stabile (2015). Specifically, we calculated five indices of relative fossoriality from seven measurements taken from the humerus and compared them with mean indices from 17 other species of

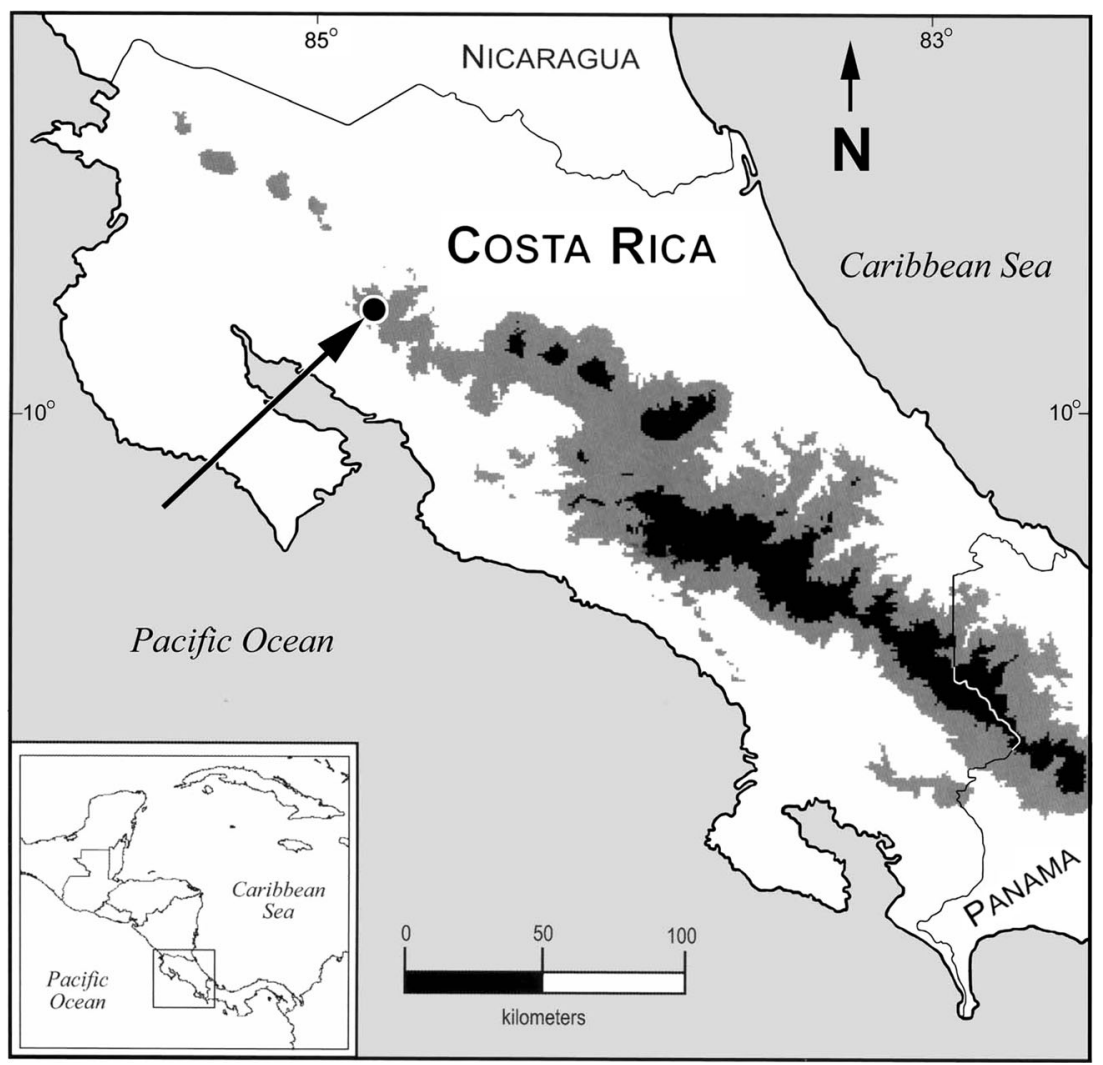

Fig. 1 Map of Costa Rica indicating the location of the community of Monteverde and the adjacent Monteverde Cloud Forest Reserve in the Tilarán Cordillera. Gray shading represents elevations of 1000-2000 m; black shading represents elevations $>2000 \mathrm{~m}$ 
Cryptotis in Woodman and Gaffney (2014). All five indices are expected to increase with increasing fossoriality (Sargis 2002; Samuels and Van Valkenburgh 2008; Woodman and Gaffney 2014; Woodman and Stabile 2015):

(1) Shoulder moment index (SMI) measures the length of the deltopectoral crest (HDPC) relative to the length of the humerus (HL), thereby gauging the size of the deltoid and pectoral muscle groups.

(2) Humeral robustness index (HRI) represents the least mediolateral diameter of the humerus (HLD) relative to $\mathrm{HL}$ and indicates the robustness of the humerus and its ability to resist bending and shearing stresses.

(3) Humeral rotation lever index (HTI) indicates the length of the teres tubercle (HTTR) relative to the length of the humerus measured along its longitudinal axis of rotation (HAR). The teres tubercle on the eulipotyphlan humerus is the insertion for the latissimus dorsi and teres major muscles and serves as a lever for rotating the humerus (Reed 1951).

(4) Teres tubercle position index (TTP) measures the relative position of the teres tubercle (HTT) along the HAR.

(5) Humeral epicondylar index (HEB) measures the width of the distal humerus (HDW) relative to the HL and represents the area available for the origins of the forearm flexor, pronator, and supinator muscles (Reed 1951).

We evaluated the overall functionality of the humerus for ambulatory locomotion versus fossoriality in two ways. First, we calculated percentile ranks for the five indices and then calculated a mean percentile rank from all indices for each species to assess the shrews along a standardized scale from 0 (more ambulatory) to 100 (more fossorial). Second, we ran a principal component analysis (PCA) on the five indices and used the scores on the first factor axis as a relative ranking for each species.

The new species from Monteverde is the only member of the $C$. thomasi group known to occur in Costa Rica, and it is readily distinguished externally from the four other species of Cryptotis in this country by its larger size and longer tail. It also has a large and distinctly-proportioned skull. The new species is most similar to $C$. endersi of Panama, from which it differs in its lack of bulbous dentition, a deep lower sigmoid notch, and several mensural characters.

Because of the number of qualitative characters that distinguish the new species, we employed multivariate analyses as post hoc tests to characterize interspecific variation in skull morphology. We carried out PCAs on correlation matrices of nine $\log _{10}$-transformed variables (CBL, MTR, M2B, PL, PO, TR, UTR, U1B, ZP) measured from the new species, 2 C. endersi from Panama, 36 C. gracilis from Costa Rica and Panama, 2 C. merriami from Costa Rica, 63 C. nigrescens from Monteverde, and 11 C. orophilus from Costa Rica. We examined relationships of overall similarity among these six species with hierarchical cluster analysis using the UPGMA linkage algorithm on 20 skull and 2 external mean variables that were available for all six species. Euclidean measures were used for similarity distances.

Specimens from the following institutions were used in this study: American Museum of Natural History, New York (AMNH); Academy of Natural Sciences of Drexel University, Philadelphia (ANSP); The Natural History Museum, London (BMNH); Field Museum of Natural History, Chicago (FMNH); University of Kansas Natural History Museum, Lawrence (KU); Los Angeles County Museum, Los Angeles (LACM); Museum of Natural Science, Louisiana State University, Baton Rouge (LSU); Museum of Comparative Zoology, Cambridge (MCZ); James Ford Bell Museum of Natural History, St. Paul (MMNH); Museo Nacional de Costa Rica, San José (MNCR); Museum of Southwestern Biology, Albuquerque (MSB); Universidad de Costa Rica, San José (UCR); University of Michigan Museum of Zoology, Ann Arbor (UMMZ); National Museum of Natural History, Washington (USNM).

\section{Results}

\section{Systematic biology}

Family Soricidae G. Fischer, 1814

Genus Cryptotis Pomel, 1848

C. thomasi group Choate, 1970

Members of the $C$. thomasi group are typically medium- to large-bodied (as measured by HB) species of Cryptotis with long skulls; reduced protoconal basin of $\mathrm{M}^{1}$ relative to hypoconal basin; proportionally low to medium-height coronoid process, the anterior border of which joins horizontal ramus of the mandible at a relatively low angle; proportionally long and low $\mathrm{P}_{3}$; unenlarged to slightly enlarged fore feet; elongate, but narrow fore claws; relatively straight humerus that, although large overall, is relatively shorter and more robust compared with humeri typical of members of the C. parvus and C. nigrescens groups (Woodman et al. 2003).

At the time of Choate's (1970) review of Middle American Cryptotis, the C. thomasi group comprised two species (Cryptotis avius, C. thomasi), one of which included seven subspecies. This group now includes at least 14 species, all but one of which occur above $1200 \mathrm{~m}$ elevation in the northern Andes or other highland regions of South America (Woodman and Péfaur 2008; Quiroga-Carmona and Molinari 2012; Quiroga-Carmona 2013; Moreno and Albuja 2014; Quiroga-Carmona and Woodman 2015). The one exception is $C$. endersi, which is known only from ca. $1200-1800 \mathrm{~m}$ elevation in highlands of western Panama (Pine et al. 2002). 
Table 1 External and skull measurements for five species of Costa Rican shrews and Cryptotis endersi from Panama

\begin{tabular}{|c|c|c|c|c|c|}
\hline C. endersi $(n=2)$ & C. monteverdensis $(n=1)$ & C. merriami $(n=2)$ & C. gracilis $(n=36)$ & C. nigrescens $(n=63)$ & C. orophilus $(n=16)$ \\
\hline \multicolumn{6}{|c|}{ Head-and-body length (HB) } \\
\hline 73,89 & 80 & $69(n=1)$ & $\begin{array}{l}67 \pm 6 \\
57-77(n=39)\end{array}$ & $\begin{array}{l}67 \pm 5 \\
53-79(n=100)\end{array}$ & $\begin{array}{l}63 \pm 7 \\
48-77(n=22)\end{array}$ \\
\hline \multicolumn{6}{|l|}{ Length of tail (TL) } \\
\hline 36,49 & 46 & 21,27 & $\begin{array}{l}37 \pm 3 \\
29-42(n=39)\end{array}$ & $\begin{array}{l}29 \pm 3 \\
20-35(n=100)\end{array}$ & $\begin{array}{l}21 \pm 2 \\
17-24(n=22)\end{array}$ \\
\hline \multicolumn{6}{|l|}{ Weight (WT) } \\
\hline- & - & $7.8(n=1)$ & $\begin{array}{l}6.9 \pm 1.8 \\
4.5-10.5(n=23)\end{array}$ & $\begin{array}{l}5.7 \pm 1.0 \\
2.5-9.0(n=93)\end{array}$ & $\begin{array}{l}5.7 \pm 1.9 \\
3-10(n=15)\end{array}$ \\
\hline \multicolumn{6}{|c|}{ Condylobasal length (CBL) } \\
\hline $20.4,21.3$ & 20.3 & $19.2,20.3$ & $\begin{array}{l}19.4 \pm 0.6 \\
18.0-20.4\end{array}$ & $\begin{array}{l}18.1 \pm 0.4 \\
16.9-19.3\end{array}$ & $\begin{array}{l}16.9 \pm 0.4 \\
16.1-17.7(n=11)\end{array}$ \\
\hline \multicolumn{6}{|c|}{ Breadth of braincase (BB) } \\
\hline $9.8,10.5$ & - & $9.4,10.4$ & $\begin{array}{l}9.7 \pm 0.4 \\
9.0-10.3(n=35)\end{array}$ & $\begin{array}{l}9.1 \pm 0.2 \\
8.6-9.7(n=55)\end{array}$ & $\begin{array}{l}8.2 \pm 0.3 \\
7.8-8.8(n=10)\end{array}$ \\
\hline \multicolumn{6}{|c|}{ Breadth of zygomatic plate (ZP) } \\
\hline $1.9,2.0$ & 1.8 & $2.1,2.5$ & $\begin{array}{l}1.8 \pm 0.1 \\
1.5-2.0\end{array}$ & $\begin{array}{l}1.9 \pm 0.1 \\
1.6-2.2\end{array}$ & $\begin{array}{l}1.5 \pm 0.1 \\
1.3-1.7\end{array}$ \\
\hline \multicolumn{6}{|c|}{ Interorbital breadth $(\mathrm{IO})$} \\
\hline $4.6,4.9$ & 5.1 & $4.7,4.8$ & $\begin{array}{l}4.6 \pm 0.2 \\
4.0-4.9\end{array}$ & $\begin{array}{l}4.2 \pm 0.2 \\
3.9-4.7\end{array}$ & $\begin{array}{l}4.0 \pm 0.1 \\
3.8-4.3\end{array}$ \\
\hline \multicolumn{6}{|c|}{ Breadth across U1s (U1B) } \\
\hline $2.6,2.7$ & 2.4 & $2.6,3.2$ & $\begin{array}{l}2.3 \pm 0.2 \\
2.0-2.6\end{array}$ & $\begin{array}{l}2.3 \pm 0.1 \\
2.1-2.5\end{array}$ & $\begin{array}{l}2.4 \pm 0.1 \\
2.2-2.5\end{array}$ \\
\hline \multicolumn{6}{|c|}{ Breadth across U3s (U3B) } \\
\hline $3.1,3.1$ & 2.9 & $3.1,3.5$ & $\begin{array}{l}2.7 \pm 0.1 \\
2.4-3.0\end{array}$ & $\begin{array}{l}2.7 \pm 0.1 \\
2.4-3.0\end{array}$ & $\begin{array}{l}2.7 \pm 0.1 \\
2.4-2.8\end{array}$ \\
\hline \multicolumn{6}{|c|}{ Breadth across M2s (M2B) } \\
\hline $5.8,5.8$ & 5.8 & $6.0,6.3$ & $\begin{array}{l}5.2 \pm 0.2 \\
4.9-5.6\end{array}$ & $\begin{array}{l}5.3 \pm 0.2 \\
4.9-5.6\end{array}$ & $\begin{array}{l}5.2 \pm 0.2 \\
4.9-5.5\end{array}$ \\
\hline \multicolumn{6}{|l|}{ Palatal Length (PL) } \\
\hline $8.6,9.3$ & 8.7 & $8.3,9.3$ & $\begin{array}{l}8.7 \pm 0.4 \\
7.8-9.3\end{array}$ & $\begin{array}{l}7.8 \pm 0.2 \\
7.2-8.6\end{array}$ & $\begin{array}{l}7.3 \pm 0.3 \\
6.9-7.8\end{array}$ \\
\hline \multicolumn{6}{|c|}{ Length of upper toothrow (TR) } \\
\hline $7.9,8.3$ & 8.1 & $7.7,8.1$ & $\begin{array}{l}7.5 \pm 0.3 \\
6.9-8.0\end{array}$ & $\begin{array}{l}7.0 \pm 0.2 \\
6.4-7.3\end{array}$ & $\begin{array}{l}6.3 \pm 0.2 \\
5.9-6.7\end{array}$ \\
\hline \multicolumn{6}{|c|}{ Length of unicuspid toothrow (UTR) } \\
\hline $2.7,2.9$ & 2.8 & $2.4,2.6$ & $\begin{array}{l}2.5 \pm 0.2 \\
2.3-2.9\end{array}$ & $\begin{array}{l}2.4 \pm 0.1 \\
2.0-2.6\end{array}$ & $\begin{array}{l}2.0 \pm 0.1 \\
1.8-2.2\end{array}$ \\
\hline \multicolumn{6}{|c|}{ Length of upper molariform toothrow (MTR) } \\
\hline $5.6,5.6$ & 5.6 & $5.6,5.9$ & $\begin{array}{l}5.2 \pm 0.2 \\
4.8-5.4\end{array}$ & $\begin{array}{l}5.1 \pm 0.2 \\
4.8-5.6\end{array}$ & $\begin{array}{l}4.5 \pm 0.1 \\
4.3-4.7\end{array}$ \\
\hline \multicolumn{6}{|c|}{ Posterior width of M1 (WM1) } \\
\hline $1.8,1.8$ & 1.8 & $1.8,2.1$ & $\begin{array}{l}1.6 \pm 0.1 \\
1.4-1.8\end{array}$ & $\begin{array}{l}1.7 \pm 0.1 \\
1.5-1.8\end{array}$ & $\begin{array}{l}1.6 \pm 0.1 \\
1.6-1.8\end{array}$ \\
\hline \multicolumn{6}{|c|}{ Mandible length (ML) } \\
\hline $6.3,7.2$ & 7.0 & $6.3,7.5$ & $\begin{array}{l}6.3 \pm 0.3 \\
5.7-6.8\end{array}$ & $\begin{array}{l}6.1 \pm 0.2 \\
5.5-6.6\end{array}$ & $\begin{array}{l}5.4 \pm 0.2 \\
4.8-5.9\end{array}$ \\
\hline \multicolumn{6}{|c|}{ Height of coronoid process $(\mathrm{HCP})$} \\
\hline $4.6,4.8$ & 4.5 & $4.7,5.4$ & $\begin{array}{l}4.0 \pm 0.2 \\
3.7-4.4\end{array}$ & $\begin{array}{l}4.3 \pm 0.2 \\
4.0-4.7\end{array}$ & $\begin{array}{l}4.1 \pm 0.1 \\
3.9-4.3\end{array}$ \\
\hline \multicolumn{6}{|c|}{ Height of coronoid valley (HCV) } \\
\hline $2.8,2.9$ & 2.8 & $2.8,3.1$ & $\begin{array}{l}2.6 \pm 0.1 \\
2.3-2.8\end{array}$ & $\begin{array}{l}2.6 \pm 0.1 \\
2.3-2.9\end{array}$ & $\begin{array}{l}2.5 \pm 0.1 \\
2.2-2.8\end{array}$ \\
\hline \multicolumn{6}{|c|}{ Height of articular condyle (HAC) } \\
\hline $3.8,4.0$ & 4.1 & $3.7,4.3$ & $\begin{array}{l}3.7 \pm 0.2 \\
3.3-4.0\end{array}$ & $\begin{array}{l}3.6 \pm 0.2 \\
3.3-4.1\end{array}$ & $\begin{array}{l}3.4 \pm 0.1 \\
3.2-3.7\end{array}$ \\
\hline \multicolumn{6}{|c|}{ Articular condyle to m3 (AC3) } \\
\hline $4.8,5.5$ & 5.3 & $4.7,5.3$ & $\begin{array}{l}5.0 \pm 0.2 \\
4.4-5.5\end{array}$ & $\begin{array}{l}4.5 \pm 0.2 \\
4.1-4.9\end{array}$ & $\begin{array}{l}4.2 \pm 0.1 \\
3.9-4.4\end{array}$ \\
\hline \multicolumn{6}{|c|}{ Breadth of articular condyle (BAC) } \\
\hline $3.0,3.4$ & 3.2 & $3.2,3.5$ & $\begin{array}{l}2.9 \pm 0.1 \\
2.7-3.2\end{array}$ & $\begin{array}{l}2.9 \pm 0.1 \\
2.6-3.1\end{array}$ & $\begin{array}{l}2.6 \pm 0.1 \\
2.4-2.7\end{array}$ \\
\hline \multicolumn{6}{|c|}{ Length of lower toothrow (TRD) } \\
\hline $6.0,6.5$ & 6.4 & $5.9,6.4$ & $\begin{array}{l}5.9 \pm 0.2 \\
5.5-6.4\end{array}$ & $\begin{array}{l}5.4 \pm 0.2 \\
5.1-5.8\end{array}$ & $\begin{array}{l}4.9 \pm 0.2 \\
4.7-5.3\end{array}$ \\
\hline Length of lower mo & row (M13) & & & & \\
\hline $4.6,4.8$ & 4.6 & $4.5,4.9$ & $\begin{array}{l}4.2 \pm 0.1 \\
4.0-4.5\end{array}$ & $\begin{array}{l}4.2 \pm 0.1 \\
3.9-4.4\end{array}$ & $\begin{array}{l}3.7 \pm 0.1 \\
3.5-3.9\end{array}$ \\
\hline Length of $\mathrm{m} 1$ (M1L & & & & & \\
\hline $1.8,1.9$ & 1.8 & $1.8,2.1$ & $\begin{array}{l}1.6 \pm 0.1 \\
1.5-1.8\end{array}$ & $\begin{array}{l}1.7 \pm 0.1 \\
1.6-1.8\end{array}$ & $\begin{array}{l}1.5 \pm 0.1 \\
1.3-1.6\end{array}$ \\
\hline
\end{tabular}

Statistics are mean $\pm \mathrm{SD}$ and range. Sample sizes are in parentheses 
To these species, we add one additional species that is of particular interest because it is the first member of the C. thomasi group to be documented north of Panama.

\section{Cryptotis monteverdensis sp. nov.}

Monteverde small-eared shrew

(Figs. 2, 3b)

Synonymy Cryptotis sp.: Timm and LaVal (2000:553); LaVal and Timm (2014:853).

Holotype Fluid-preserved adult female with skull and left humerus removed, University of Kansas Natural History Museum (KU) number 134852; found dead in the Monteverde Cloud Forest Reserve (Fig. 1) on 13 August 1973 by Jerry James and preserved in formalin by his father, Walter James, who presented it to Richard K. LaVal (field number 3115). Cranium is damaged and fragile: portions of left frontal and both parietals missing; petrosals separate; left upper first unicuspid (LU') missing (Fig. 2).

Type locality Costa Rica, Puntarenas Province, Monteverde, Monteverde Cloud Forest Reserve, in "cloud forest at [the continental] divide" (ca. $10^{\circ} 18^{\prime} \mathrm{N}, 84^{\circ} 47^{\prime} \mathrm{W}$ ); the highest elevations in the 1973 reserve, including the continental divide, are at ca. $1550 \mathrm{~m}$ (Fig. 1).

Distribution Known only from Lower Montane Wet Forest at the type locality; this species is probably restricted to the highest elevations of Costa Rica's Cordillera de Tilarán.

Etymology The specific epithet monteverdensis is derived from the type locality for this species; it recognizes the Monteverde Cloud Forest Reserve, the Monteverde Conservation League, and the residents of the Monteverde community for their strong conservation efforts to preserve the habitat of this and other poorly known species.

Nomenclatural statement A life sciences identifier (SID) number was obtained for the new species (C. monteverdensis); urn:Isid:zoobank.org: pub:A9C9F3DB3AED-42AA-9604-9209269961FC.

Diagnosis A large small-eared shrew of the C. thomasi species group, this is the largest soricid in Costa Rica (CBL
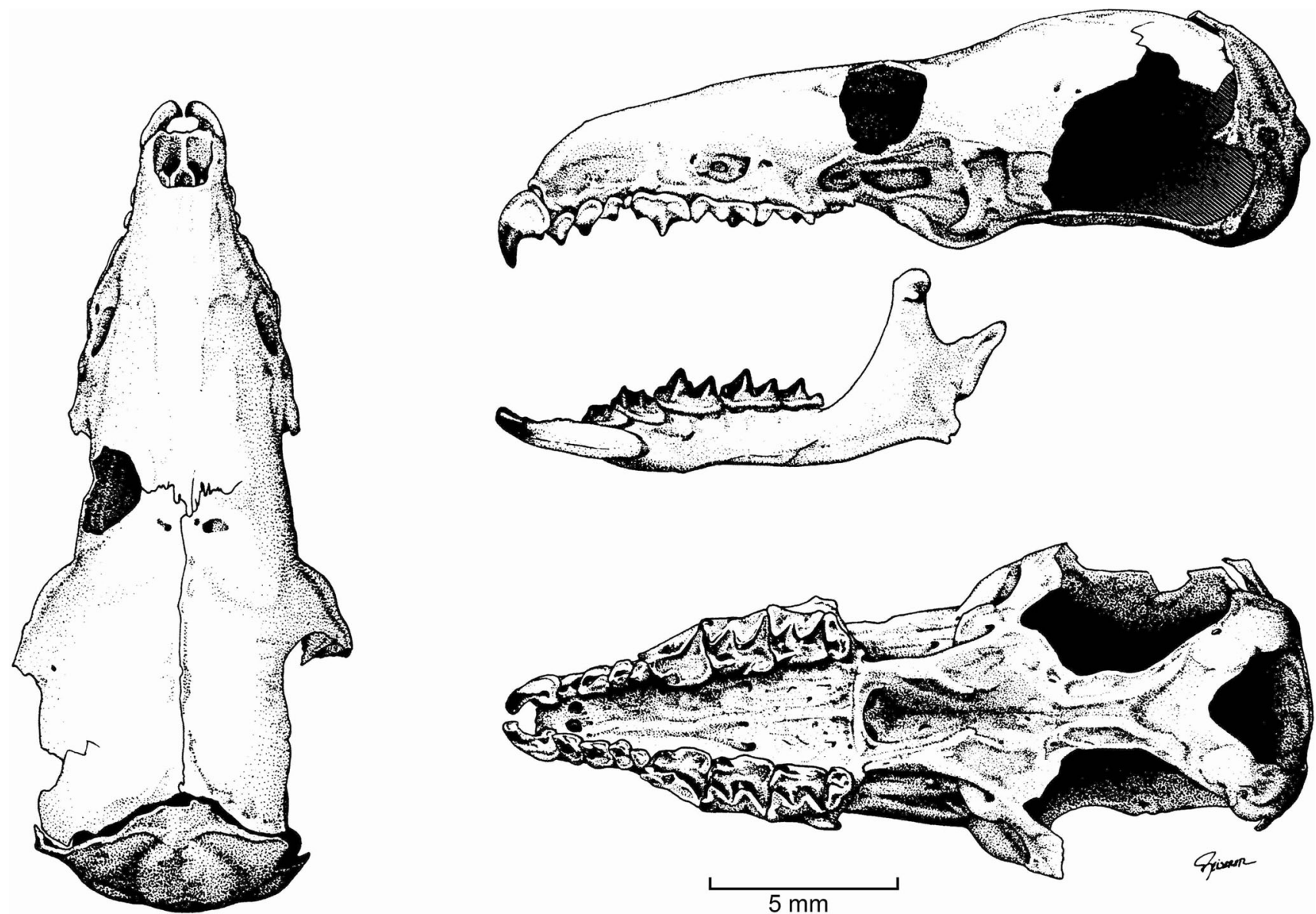

Fig. 2 Dorsal, lateral, and ventral views of the cranium and lateral view of the mandible of the holotype of C. monteverdensis nov. sp. (KU 134852) 


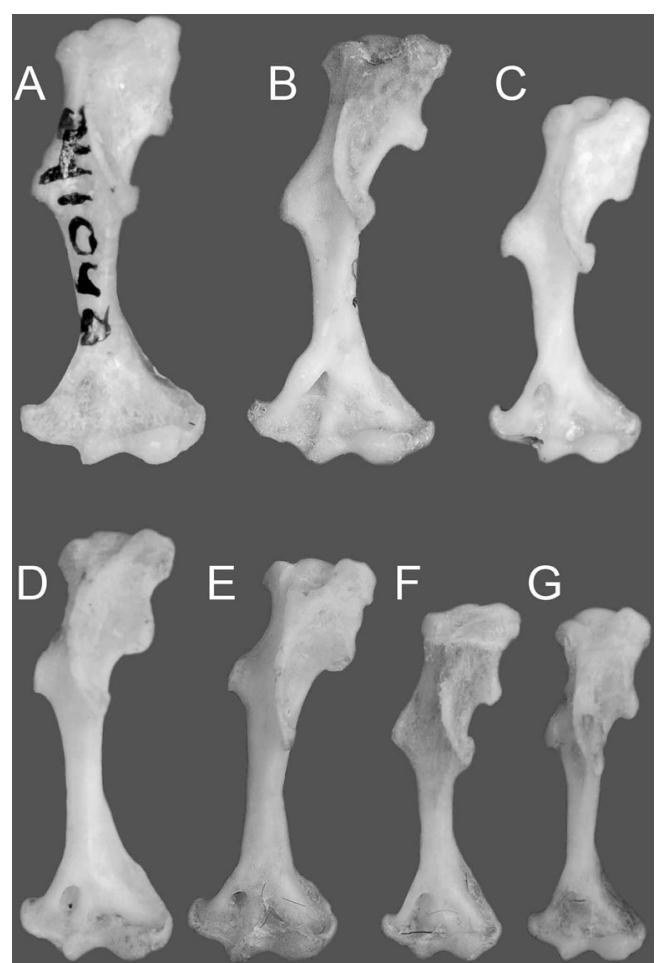

Fig. 3 Anterior aspect of left humeri of A C. endersi, B C. monteverdensis, C C. gracilis, D C. nigrescens, E C. merriami, $\mathrm{F}$ C. tropicalis, G C. parvus. The humeri of C. tropicalis and C. parvus are proxies for $C$. orophilus, another member of the $C$. parvus group

typically shorter in Costa Rican C. merriami; HB and CBL typically shorter in C. gracilis, C. nigrescens, and C. orophilus; Table 1). The species is characterized by an absolutely and proportionally long tail (typically shorter in most individuals of most other species in the genus; Table 2); rostrum of moderate length (typically longer in Costa Rican C. merriami; much longer in C. gracilis); interorbital region proportionally broad (typically narrower in C. gracilis, C. merriami, C. nigrescens, C. orophilus; much narrower in $C$. endersi); zygomatic plate proportionally narrow (broader in C. merriami, C. nigrescens); palate moderately narrow (proportionally much broader in Costa Rican C. merriami, C. orophilus, but typically narrower in C. endersi and much narrower in C. gracilis); dentition not bulbous (bulbous in C. endersi, C. merriami); upper toothrow long and uncrowded (proportionally shorter in C. endersi, C. gracilis, $C$. nigrescens, $C$. orophilus); unicuspid toothrow proportionally long (typically shorter in C. endersi, C. gracilis, C. nigrescens; much shorter in Costa Rican C. merriami, C. orophilus); coronoid process short (typical higher in C. nigrescens; much higher in Costa Rican C. merriami, C. orophilus); moderately long distance from the superior tip of the articular process to the posterior border of $\mathrm{M}_{3}$ (typically longer distance in $C$. gracilis; typically shorter in C. merriami, C. nigrescens); lower sigmoid notch deep (very shallow in C. merriami, $C$. nigrescens); and entoconid of $\mathrm{M}_{3}$ vestigial (lacking on $\mathrm{M}_{3}$ of $C$. merriami, C. orophilus; well developed on $\mathrm{M}_{3}$ of $C$. gracilis).

Description of the holotype A larger Cryptotis as measured by HB ( $80 \mathrm{~mm}$; compared with $74 \pm 8 \mathrm{~mm}$ for the genus) and CBL (20.3 mm; compared with $19.6 \pm 1.7 \mathrm{~mm}$ for the genus; Table 1); tail long, about $58 \%$ of HB (compared with $40 \% \pm 7$ for the genus; Table 2). The dark pelage of the fluid-preserved holotype appears to be similar in coloration to C. gracilis; ventrum nearly as dark as dorsum; dorsal guard hairs 7 $8 \mathrm{~mm}$ long. Fore feet not particularly broad; fore claws elongate, but narrow. Rostrum of moderate length (PL/ $\mathrm{CBL}=42.9 \%$; Fig. 2) for the genus $(43.4 \% \pm 1.1 \mathrm{~mm})$; interorbital region proportionally broad $(\mathrm{IO} / \mathrm{CBL}=25.1 \%)$ among Costa Rican soricids (Table 2); a medium to large size, widely rounded foramen (foramen orbitalium of Bühler 1964) opens laterally on each frontal, the two foramina widely separated; no foramen dorsal to external capitular facet (McDowell 1958); tiny foramen (associated with sinus canal) present posterior to each external capitular facet; no foramen on posteromedial edge of caudal tympanic process of petrosal; zygomatic plate moderately narrow $(\mathrm{ZP} / \mathrm{CBL}=8.9 \%$; compared with $9.8 \% \pm 1.0$ for the genus), anterior border aligned with anterior edge of $\mathrm{M}^{1}$ metastyle; posterior border of zygomatic plate roundly concave, aligned with $\mathrm{M}^{3}$ parastyle and with the posterior one third of the maxillary process; palate moderately narrow $(\mathrm{M} 2 \mathrm{~B} / \mathrm{CBL}=28.6$; compared with $29.3 \% \pm 1.2$ for the genus); upper toothrow uncrowded, proportionally long $(\mathrm{TR} / \mathrm{CBL}=39.9 \%$; compared with $38.2 \% \pm 1.0$ for the genus); dentition not bulbous; teeth moderately pigmented: tips of all unicuspids pigmented; medium red to dark red on tips of cones (except hypocone), styles, and cristae of $\mathrm{P}^{4}$ and $\mathrm{M}^{1-3}$ and extending into protoconal (but not hypoconal) basins of $\mathrm{M}^{1-2}$; unicuspid toothrow proportionally long $(\mathrm{UTR} / \mathrm{CBL}=13.8 \%$; compared with $12.8 \% \pm 0.6$ for the genus); posteroventral borders of unicuspids shallowly concave in labial view of the cranium; $\mathrm{U}^{4}$ aligned with the unicuspid toothrow in occlusal view and visible in labial view; occlusal area of $\mathrm{U}^{4}$ about $51 \%$ that of $\mathrm{U}^{3} ; \mathrm{P}^{4}, \mathrm{M}^{1}$, and $\mathrm{M}^{2}$ unrecessed on their posterior borders; protoconal basin of $\mathrm{M}^{1}$ reduced relative to hypoconal basin; $\mathrm{M}^{3}$ complex, with paracrista, paracone, precentrocrista, mesostyle, postcentrocrista, and metacone; protocone of $\mathrm{M}^{3}$ well developed, whereas hypocone is poorly developed. Mandible relatively long and of moderate breadth for the genus; coronoid process short $(\mathrm{HCP} / \mathrm{LM}=64.3 \%$; compared with $71.2 \% \pm 5.6$ for the genus); anterior border of coronoid process joins horizontal ramus of the mandible at a relatively low angle; moderately long distance from the superior tip of the articular process to the posterior border of $\mathrm{M}_{3}$ (AC3/ $\mathrm{ML}=75.7 \%$; compared with $78.1 \% \pm 5.2$ for the genus); articular process tall and narrow; inferior sigmoid notch deep; posterior border of cingulum of lower incisor aligned with 
Table 2 External and skull indices for five species of Costa Rican shrews and Cryptotis endersi from Panama

\begin{tabular}{|c|c|c|c|c|c|}
\hline C. endersi $(n=2)$ & C. monteverdensis $(n=1)$ & C. merriami $(n=2)$ & C. gracilis $(n=36)$ & C. nigrescens $(n=63)$ & C. orophilus $(n=11)$ \\
\hline \multicolumn{6}{|c|}{ Relative length of tail (TL/HB\%) } \\
\hline \multirow[t]{2}{*}{49,55} & 58 & $39(n=1)$ & $55 \pm 7$ & $43 \pm 5$ & $34 \pm 4$ \\
\hline & & & $45-68(n=39)$ & $32-57(n=100)$ & $29-42(n=22)$ \\
\hline \multicolumn{6}{|c|}{ Relative length of rostrum (PL/CBL\%) } \\
\hline \multirow[t]{2}{*}{$42.2,43.7$} & 42.9 & $43.2,45.8$ & $44.7 \pm 1.1$ & $42.8 \pm 0.7$ & $43.0 \pm 0.9$ \\
\hline & & & $42.6-47.4$ & $41.4-44.6$ & $41.7-44.3$ \\
\hline \multicolumn{6}{|c|}{ Relative breadth of interorbital region (IO/CBL\%) } \\
\hline \multirow[t]{2}{*}{$22.5,23.0$} & 25.1 & $24.5,23.6$ & $23.7 \pm 0.8$ & $23.3 \pm 0.8$ & $23.8 \pm 0.5$ \\
\hline & & & $21.6-25.1$ & $21.5-24.6$ & $22.9-24.7$ \\
\hline \multicolumn{6}{|c|}{ Relative breadth of zygomatic plate (ZP/CBL\%) } \\
\hline \multirow[t]{2}{*}{$8.9,9.8$} & 8.9 & $10.9,12.3$ & $9.0 \pm 0.7$ & $10.6 \pm 0.7$ & $8.9 \pm 0.6$ \\
\hline & & & $7.4-10.3$ & $8.8-12.2$ & $8.1-9.8$ \\
\hline \multicolumn{6}{|c|}{ Relative length of upper toothrow (TR/CBL\%) } \\
\hline \multirow[t]{2}{*}{$38.7,39.0$} & 39.9 & $40.1,39.9$ & $38.6 \pm 0.9$ & $38.4 \pm 0.7$ & $37.2 \pm 0.6$ \\
\hline & & & $37.1-40.2$ & $36.9-39.8$ & $36.3-38.5$ \\
\hline \multicolumn{6}{|c|}{ Relative length of unicuspid toothrow (UTR/CBL\%) } \\
\hline \multirow[t]{2}{*}{$13.2,13.6$} & 13.8 & $12.5,12.8$ & $13.1 \pm 0.6$ & $13.0 \pm 0.6$ & $12.1 \pm 0.7$ \\
\hline & & & $11.7-14.4$ & $11.3-14.3$ & $11.2-13.7$ \\
\hline \multicolumn{6}{|c|}{ Relative breadth of palate (M2B/CBL\%) } \\
\hline \multirow[t]{2}{*}{$27.2,28.4$} & 28.6 & $31.3,31.0$ & $26.9 \pm 0.8$ & $29.3 \pm 0.8$ & $30.9 \pm 0.6$ \\
\hline & & & $25.5-28.3$ & $27.1-30.9$ & $29.9-31.7$ \\
\hline \multicolumn{6}{|c|}{ Relative height of coronoid process (HCP/ML\%) } \\
\hline \multirow[t]{2}{*}{$63.9,76.2$} & 64.3 & $74.6,72.0$ & $64.2 \pm 3.4$ & $70.5 \pm 1.9$ & $75.2 \pm 3.6$ \\
\hline & & & $56.7-70.2$ & $66.7-74.6$ & $70.9-83.3(n=20)$ \\
\hline \multicolumn{6}{|c|}{ Relative distance from articular condyle to $\mathrm{m} 3$ (AC3/M1\%) } \\
\hline \multirow[t]{2}{*}{$76.2,76.4$} & 75.7 & $74.6,70.7$ & $79.6 \pm 2.6$ & $72.6 \pm 2.4$ & $76.8 \pm 3.6$ \\
\hline & & & $74.6-85.0$ & $66.7-77.8$ & $70.7-85.4(n=20)$ \\
\hline
\end{tabular}

Statistics are mean \pm SD and range. Sample sizes are in parentheses

posterior edge of hypoconid of $\mathrm{P}_{4} ; \mathrm{P}_{3}$ proportionally long and low; entoconid of $\mathrm{M}_{3}$ vestigial. Humerus similar to that of C. endersi (Fig. 3): shaft of the humerus moderately long and broad; head of humerus dorsoventrally elongate; teres tubercle of humerus somewhat elongate.

Comparisons Measurements and indices for C. monteverdensis and the species with which it is compared below are presented in Tables 1 and 2.

C. endersi: C. monteverdensis has a proportionally longer tail and generally shorter CBL; broader interorbital region; proportionally broader palate; proportionally longer upper toothrow and unicuspid toothrow; dentition not bulbous; and deep lower sigmoid notch.

C. gracilis: C. monteverdensis differs in being larger in most dimensions (particularly HB and CBL) and having an absolutely longer tail; relatively shorter, but broader rostrum; broader interorbital region and palate; absolutely and proportionally longer upper toothrow; proportionally shorter distance from superior tip of articular process to posterior border of $\mathrm{M}_{3}$; and vestigial (rather than well-developed) entoconid of $\mathrm{M}_{3}$.

C. merriami: C. monteverdensis differs from Costa Rican C. merriami in its generally larger size and its absolutely and relatively longer tail; proportionally shorter rostrum; relatively broader interorbital region; relatively narrower zygomatic plate and palate; longer upper toothrow and proportionally longer unicuspid toothrow; longer, broader mandible with relatively lower coronoid process and longer distance from articular process to $\mathrm{M}_{3}$; tall, narrow articular process; deep lower sigmoid notch; dentition not bulbous; vestigial entoconid with hypoconid on $\mathrm{M}_{3}$.

Cryptotis nigrescens: C. monteverdensis is typically larger and has a proportionally and absolutely longer tail; proportionally broader interorbital region; narrower zygomatic plate; relatively longer upper toothrow and unicuspid toothrow; longer, broader mandible with a proportionally shorter coronoid process and a longer distance between the articular process 
and $\mathrm{M}_{3}$; tall and narrow articular process; deep lower sigmoid notch.

C. orophilus: $C$. monteverdensis is a larger species with a longer tail; noticeably darker dorsal and ventral pelage; proportionally broader interorbital region; relatively narrower palate; longer upper toothrow and unicuspid toothrow; longer and broader mandible with relatively shorter coronoid process; taller and narrower articular process; vestigial entoconid with hypoconid on $\mathrm{M}_{3}$.

\section{Multivariate analyses}

In our nine-variable PCA of $C$. endersi and the five species of Costa Rican Cryptotis, six variables contributed strongly to the first factor axis (Table 3), providing a measure of overall size. The second axis is strongly influenced by three negatively weighted variables representing breadth of the palate and breadth of the zygomatic plate (M3B, U1B, ZP). On a plot of factor scores on these first two factor axes (Fig. 4), the distributions of the different species overlap along each of the individual axes. Along the first factor axis, for example, the three most abundant species-C. orophilus (smallest), C. nigrescens (intermediate), and C. gracilis (largest) - overlap considerably in size. They also overlap partly (C. nigrescens and $C$. gracilis) or completely (C. orophilus and $C$. nigrescens) along the second axis. Together, however, the two axes separate the species with minimal overlap as a result of the relatively broader palate and zygomatic plate of C. orophilus in contrast to a relatively narrower palate and zygomatic plate of similar-sized $C$. nigrescens and the even narrower palate and zygomatic plate of $C$. gracilis. In contrast, C. endersi, C. merriami, and C. monteverdensis are generally larger species separated from each other and from C. orophilus, C. nigrescens, and C. gracilis by progressively broader palate and zygomatic plate.

Table 3 Component loadings and eigenvalues from the first two factor axes of a PCA of nine skull variables from six species of Cryptotis

\begin{tabular}{lcc}
\hline Component loadings & & \\
\hline Variables & 1 & 2 \\
\hline TR & 0.954 & 0.190 \\
CBL & 0.950 & 0.213 \\
PL & 0.889 & 0.331 \\
PO & 0.852 & 0.178 \\
UTR & 0.846 & 0.226 \\
MTR & 0.827 & -0.132 \\
M2B & 0.539 & -0.721 \\
U1B & 0.440 & -0.725 \\
ZP & 0.375 & -0.542 \\
Eigenvalues & 5.355 & 1.631 \\
Percent of total & & \\
variance explained & 59.5 & 18.1 \\
\hline
\end{tabular}

The cophenetic correlation coefficient from our hierarchical cluster analysis $(\mathrm{CPCC}=0.863)$ indicates a high degree of fit between the original data and the distances calculated among species. The resulting phenogram (Fig. 5) divides the six species into two primary groupings, one comprising the two $C$. thomasi group shrews (C. endersi, C. monteverdensis), and a second composed of the remaining four species. Within the larger of the two primary groupings, the two members of the $C$. nigrescens group (C. merriami, C. nigrescens) are associated. These two species are successively associated with C. gracilis and then $C$. orophilus.

\section{Humerus function}

The humerus of the holotype of $C$. monteverdensis yielded the following measurements: $\mathrm{HAR}=7.95 \mathrm{~mm}$, $\mathrm{HDPC}=3.61 \mathrm{~mm}, \mathrm{HDW}=3.58 \mathrm{~mm}, \mathrm{HL}=8.33 \mathrm{~mm}$, HLD $=0.82 \mathrm{~mm}$, HTT $=3.63 \mathrm{~mm}$, and HTTR $=1.45 \mathrm{~mm}$. From these, we calculated five indices of locomotory function based on the humerus that we present in Table 4, along with mean indices from 17 other species of Cryptotis (Woodman and Gaffney 2014). We used percentile ranks to standardize the indices, and we calculated a mean percentile rank for each species (Table 4). The mean percentile rank provides a relative measure of locomotory function based on the measures used to calculate it and the groups tested. Cryptotis monteverdensis, like the two other species of the $C$. thomasi group included in this analysis (C. endersi, $C$. meridensis), falls decisively on the more ambulatory portion of this scale.

In a second test, we carried out a PCA on the five humerus indices from $C$. monteverdensis and the 17 species of other small-eared shrews. All of the indices except SMI loaded heavily $(>0.940)$ on the first factor axis, indicating that factor 1 scores provide a reasonable summary of the indices and, thereby, a measure of relative locomotory habitus function (Woodman and Gaffney 2014; Woodman and Stabile 2015). The ranking from this analysis is presented in Table 5. The humerus of $C$. monteverdensis has a negative ranking that, in agreement with the mean percentile rankings, indicates a morphology more adapted for ambulatory behavior. Because SMI did not accord with the other indices in loading strongly on the first factor axis, we recalculated mean percentile ranks without it (not shown). The resulting rankings provided the same order of species as in Table 5, with the exception that the relative positions of $C$. goodwini and C. cavatorculus are reversed.

Although $C$. monteverdensis plots as more ambulatory within the genus Cryptotis based on humerus dimensions, mean percentile ranks and PC1 scores calculated for both of the other two species of shrews at Monteverde, C. merriami and $C$. nigrescens, indicate that they are even more ambulatory in their locomotory behavior than is $C$. monteverdensis (Tables 4, 5). 
Fig. 4 Plot of scores for six species of Cryptotis on PCA factor axes 1 and 2. See Table 3.

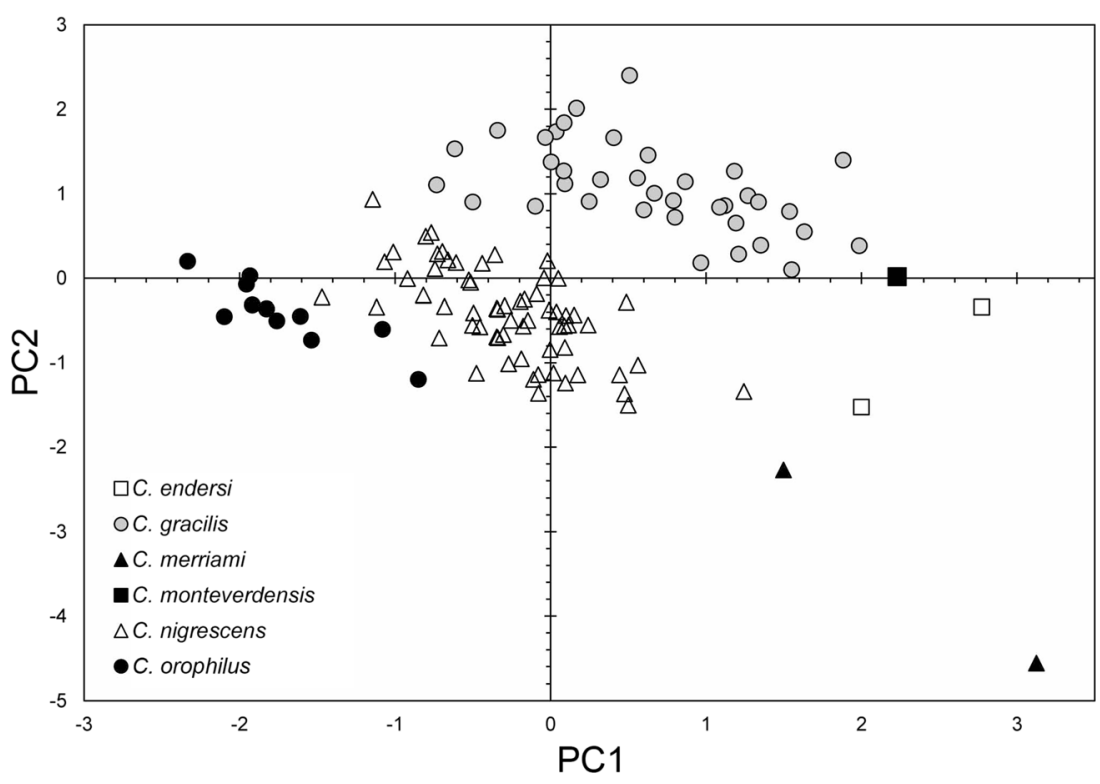

\section{Discussion}

The reserve complex at Monteverde, the type locality of C. monteverdensis, currently includes a number of public and private protected lands that are often collectively referred to as the Children's Eternal Forest (Bosque Eterno de los Niños). These include the Monteverde Cloud Forest Preserve, International Children's Rain Forest Reserve, San Ramón Reserve, and Tropical Science Center Reserve, although names vary depending upon the source. Together, these reserves now encompass approximately 20,000 ha on both the Pacific and Atlantic slopes and protect an elevational transect from 500 to $1880 \mathrm{~m}$.

The considerable variation in elevation results in complex habitats in the Monteverde region. Six major Holdridge life zones are found sequentially from $700 \mathrm{~m}$ in elevation on the dryer and more seasonal Pacific slopes, up and across the continental divide, and back down to $500 \mathrm{~m}$ on the wet

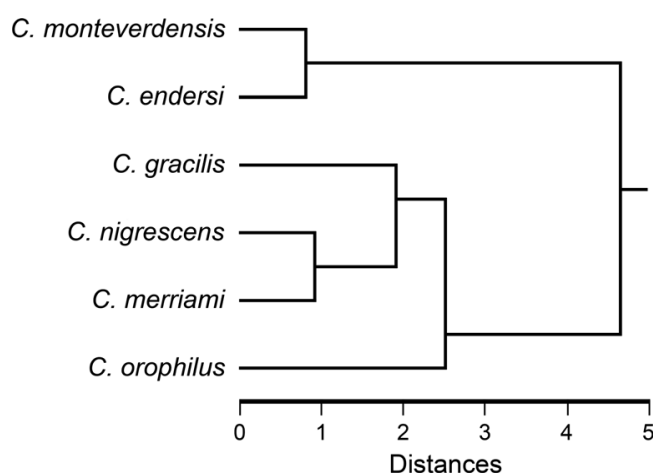

Fig. 5 Phenogram of six species of Cryptotis from hierarchical cluster analysis of 22 mean variables
Caribbean slopes: Premontane Moist Forest (700-1300 m), Premontane Wet Forest (1300-1500 m), Lower Montane Wet Forest (1500-1650 m), Lower Montane Rain Forest (1650-1880 m), Premontane Rain Forest (700-1600 m), and Tropical Wet Forest $(500-700 \mathrm{~m})$ (modified from Haber 2000). At Monteverde, the informal formation referred to as "cloud forest" generally signifies Premontane Wet Forest, Lower Montane Wet Forest, and Lower Montane Rain Forest life zones. All three species of Cryptotis at Monteverde have been found in Lower Montane Wet Forest, however, the most abundant species, C. nigrescens, occurs in all life zones except Tropical Wet Forest (Timm and LaVal 2016).

Average rainfall in the Lower Montane Wet Forest life zone historically averaged $3000-5000 \mathrm{~mm} /$ year at Monteverde, but in the past 20-25 years, rainfall has declined considerably (Haber 2000). Outside the Monteverde Reserve at $1460 \mathrm{~m}$ (Premontane Wet Forest), average annual temperature during the years 1956 to 1995 was $18.5^{\circ} \mathrm{C}$ and mean annual precipitation was $2519 \mathrm{~mm}$, with a range of 1715-3240 mm/year. Wind-driven moisture in the form of clouds is a critical component that can add $>800 \mathrm{~mm}$ to total water input in a given year at Monteverde (Clark et al. 2000). Mist frequency, however, also has declined in the region, further decreasing available water (Pounds et al. 1999). The physical and biotic environments and the history of Monteverde are detailed in Nadkarni and Wheelwright (2000).

The sector where Jerry James encountered the specimen of C. monteverdensis in 1973 is part of the original reserve at the top of the continental divide. Vegetation here is cloud forest (i.e., Lower Montane Wet Forest) with an average canopy height of 25-35 m. This was part of the forest originally preserved by the Quaker community of Monteverde to protect 
Table 4 Mean indices, percentile ranks, and mean percentile ranks for 18 species of Cryptotis

\begin{tabular}{|c|c|c|c|c|c|c|c|c|c|c|c|}
\hline & \multicolumn{5}{|c|}{ Mean indices } & \multicolumn{5}{|c|}{ Percentile ranks mean } & \multirow[t]{2}{*}{ Mean percentile ranks } \\
\hline & SMI & HRI & HTI & TTP & HEB & SMI & HRI & HTI & TTP & HEB & \\
\hline C. parvus & 42 & 9 & 17 & 40 & 36 & 14 & 14 & 11 & 19 & 22 & 16 \\
\hline C. nigrescens & 43 & 9 & 18 & 39 & 35 & 31 & 14 & 28 & 14 & 11 & 19 \\
\hline C. merriami & 44 & 9 & 17 & 38 & 35 & 53 & 14 & 11 & 8 & 11 & 19 \\
\hline C. merus & 46 & 9 & 12 & 37 & 36 & 86 & 14 & 3 & 3 & 22 & 26 \\
\hline C. endersi & 42 & 9 & 20 & 41 & 42 & 14 & 14 & 42 & 25 & 39 & 27 \\
\hline C. tropicalis & 45 & 10 & 18 & 42 & 34 & 72 & 36 & 28 & 33 & 3 & 34 \\
\hline C. phillipsii & 42 & 11 & 23 & 42 & 42 & 14 & 53 & 53 & 33 & 39 & 38 \\
\hline C. meridensis & 44 & 10 & 18 & 45 & 40 & 53 & 36 & 28 & 42 & 31 & 38 \\
\hline C. monteverdensis & 43 & 10 & 18 & 46 & 43 & 31 & 36 & 28 & 53 & 47 & 39 \\
\hline C. gracilis & 46 & 11 & 21 & 46 & 44 & 86 & 53 & 47 & 53 & 53 & 58 \\
\hline C. mexicanus & 44 & 11 & 25 & 49 & 46 & 53 & 53 & 58 & 72 & 58 & 59 \\
\hline C. mccarthyi & 43 & 13 & 30 & 46 & 51 & 31 & 81 & 64 & 53 & 67 & 59 \\
\hline C. goodwini & 41 & 12 & 32 & 51 & 53 & 3 & 64 & 81 & 89 & 86 & 64 \\
\hline C. celaque & 45 & 13 & 31 & 49 & 51 & 72 & 81 & 69 & 72 & 67 & 72 \\
\hline C. cavatorculus & 50 & 13 & 32 & 48 & 52 & 97 & 81 & 81 & 64 & 78 & 80 \\
\hline C. oreoryctes & 44 & 13 & 34 & 51 & 54 & 53 & 81 & 97 & 89 & 92 & 82 \\
\hline C. mam & 46 & 13 & 32 & 51 & 52 & 86 & 81 & 81 & 89 & 78 & 83 \\
\hline C. lacertosus & 44 & 15 & 33 & 51 & 58 & 53 & 97 & 92 & 89 & 97 & 86 \\
\hline
\end{tabular}

The mean percentile ranks serve as a general measure of relative locomotory function, from more ambulatory (low ranks) to more fossorial (high ranks). Species are listed in order by increasing mean percentile rank (see Woodman and Gaffney 2014; Woodman and Stabile 2015)

Abbreviations of functional indices: SMI shoulder moment index, HRI humeral robustness index, HTI humeral rotation lever index, TTP teres tubercle position index, $H E B$ humeral epicondylar index

their watershed, and, in 1972, 328 ha on the Pacific slopes up to the continental divide were established as the Monteverde Cloud Forest Preserve, owned and managed by the Tropical Science Center of San José. In the early 1970s, a single trail led up from the community to the divide. This trail was primarily used by hunters on horseback and by local residents to access the Peñas Blancas Valley on the Atlantic slope, and it is likely that Jerry James was along this trail or close to it when he discovered the fresh body of the holotype of C. monteverdensis near the continental divide. James was the son of two of the original Quaker founders of Monteverde, Walter and Mary James, and he served as one of the first guides to naturalists who came to see and study the elfin and cloud forests at the divide. He also discovered the Monteverde endemic golden toad (Bufo periglenes), which is now extinct.

The Monteverde region of the Tilarán Cordillera is currently one of the best sampled areas for small mammals in Central America. The Lower Montane Wet Forest life zone of Monteverde has a diverse mammalian fauna that consists of at least 90 species representing 11 orders and 32 families. Documented species include 5 marsupials, 3 shrews (including C. monteverdensis), 33 bats, 3 primates, 2 armadillos, 1 sloth, 1 anteater, 2 rabbits, 3 squirrels, 12 long-tailed rats and mice, 1 pocket gopher, 1 porcupine, 1 paca, 1 agouti, 1 fox, 4 mustelids, 1 skunk, 5 procyonids, 6 cats, 2 peccaries, 1 brocket deer, and 1 tapir (Timm and LaVal 2000, 2016). Of these, only the white-lipped peccary (Tayassu pecari) is extirpated from the region.

The Monteverde region is an area of considerable biological interest, in part because of its complex, spectacular habitats. It has also proven to be a region of biotic transitions and endemism (Nadkarni and Wheelwright 2000). Among the mammals, the rodents Nephelomys devius, Oligoryzomys vegetus, Reithrodontomys creper, Rheomys raptor, Tanyuromys aphrastus, and an undescribed species of Reithrodontomys reach their northernmost distributions at Monteverde, whereas, the spiny pocket mouse, Heteromys nubicolens, and the shrew, C. merriami, reach their southern limits (Woodman 2000; Anderson and Timm 2006). The holotype of $C$. monteverdensis is from an elevation of ca. $1550 \mathrm{~m}$. Members of the $C$. thomasi group, to which it belongs, are high-elevation species that are not known to occur below $1200 \mathrm{~m}$, and they often are restricted to much higher elevations (Woodman and Péfaur 2008). The Cordillera de Tilarán in no place reaches an elevation of $2000 \mathrm{~m}$, hence the potential elevational-and areal-distribution of C. monteverdensis is almost certainly restricted to the 
Table 5 Factor 1 scores from PCA of five humerus indices

\begin{tabular}{lc}
\hline Species & Factor 1 score \\
\hline C. merus & -1.39 \\
C. merriami & -1.18 \\
C. parvus & -1.17 \\
C. nigrescens & -1.16 \\
C. tropicalis & -0.88 \\
C. endersi & -0.78 \\
C. meridensis & -0.49 \\
C. monteverdensis & -0.41 \\
C. phillipsii & -0.38 \\
C. gracilis & -0.08 \\
C. mexicanus & 0.23 \\
C. mccarthyi & 0.70 \\
C. celaque & 0.89 \\
C. goodwini & 0.95 \\
C. cavatorculus & 1.07 \\
C. mam & 1.19 \\
C. oreoryctes & 1.29 \\
C. lacertosus & 1.60 \\
\hline
\end{tabular}

The factor scores serve as a general indication of relative locomotory function, from more ambulatory (more negative scores) to more fossorial (more positive scores). Species are listed in order by increasing factor 1 score (see Woodman and Gaffney 2014; Woodman and Stabile 2015)

Tilarán Cordillera, and it is probably endemic to Monteverde. If so, it is the only mammal species endemic to the reserves.

Beginning in the mid-1980s, we exerted significant efforts throughout the Monteverde region to obtain additional specimens of C. monteverdensis. We used a variety of trap types to survey in all major habitats, with the most effective means for capturing shrews being the pitfall. Local residents assisted by preserving specimens found dead along trails and roads and brought in by domestic cats. These efforts have added to the total number of shrews and other mammals available for study, although we failed so far to locate a population of the new species. Shrews are rarely seen in the lush habitats of the reserve or in the Monteverde community, but they are abundant in certain habitats. Of 125 preserved specimens of soricids obtained from the Monteverde region from 1973 to the present, we identified 122 C. nigrescens, 2 C. merriami, and only the single specimen of C. monteverdensis (Appendix). Cryptotis endersi from western Panama is similarly rare. It is known from only two specimens collected nearly 39 years apart from two separate localities (Pine et al. 2002), attesting to how little is known about these northernmost members of the $C$. thomasi species complex.

Climate change has been documented at Monteverde as a trend of reduced rainfall, reduced moisture from the orographic cloud bank, severe dry seasons, and exceptionally hot days during the dry season. Pounds et al. (1999) postulated that these climatic changes are responsible for the multispecies crash in amphibian populations seen at Monteverde as well as a net movement upslope of premontane breeding birds. Climate change may also be exacerbating the effects of the chrytrid fungus on anurans at Monteverde. The small but thriving population of golden toads was intact in 1986, but by 1987 only a few remained, and by 1988, the species was extinct. Changes in bat distributions in the Monteverde area have been documented by Timm and LaVal (2000); LaVal (2004), and LaVal et al. (2016). Whether or not the climatic changes that have occurred in the Monteverde region have already impacted the enigmatic C. monteverdensis is unknowable at this point. It is certain, however, that this and other high-elevation species in Central America (e.g., Woodman 2015; Woodman et al. 2012) are currently at risk under current climatic trends in the region.

Acknowledgments We are grateful to the late Jerry and Walter James for their commitment to saving smelly dead shrews in the belief that someday someone might find them of biological interest. Richard K. and Margaret L. LaVal greatly assisted our efforts over many years in documenting the amazing fauna of Monteverde. We are grateful to them and to other residents of Monteverde for saving and donating a number of scientifically informative specimens over the years and for their efforts in conserving the natural world around them. We thank the following curators and collection managers for loans or for permission to examine specimens under their care: Robert S. Voss (American Museum of Natural History), Ted Daeschler (Academy of Natural Sciences of Drexel University), Paula Jenkins (The Natural History Museum), Lawrence R. Heaney and Bruce D. Patterson (Field Museum of Natural History), Jim Dines (Los Angeles County Museum), Jacob A. Esselstyn (Museum of Natural Science, Louisiana State University), Judith M. Chupasko (Museum of Comparative Zoology), Sharon A. Jansa (James Ford Bell Museum of Natural History), Francisco J. Durán A. (Museo Nacional de Costa Rica), Joseph A. Cook (Museum of Southwestern Biology), Bernal Rodríguez Herrera (Universidad de Costa Rica), and Cody W. Thompson (University of Michigan Museum of Zoology). Deb Bennett assisted with the map used as Fig. 1, and Randall S. Reiserer produced the cranial drawings used as Fig. 2. Alfred L. Gardner and two anonymous reviewers provided valuable suggestions on earlier versions of this manuscript. Any use of trade, product, or firm names is for descriptive purposes only and does not imply endorsement by the US government.

\section{Compliance with ethical standards}

Ethical standards This article does not contain any studies with human participants performed by any of the authors. All procedures performed in studies involving animals were in accordance with the ethical standards of the institutions at which the studies were conducted.

Conflict of interest The authors declare that they do not have conflict of interest.

Appendix Specimens Examined

C. endersi $(n=2)$-PANAMA: BocAS DEL TORO: Cylindro (ANSP 20955-holotype); Chiriquí/Bocas del Toro; Cerro Bollo (31 $\frac{1}{2} \mathrm{~km} \mathrm{E}$ Escopeta), 1800-1856 (USNM 54048).

C. gracilis $(n=45)$ COSTA RICA: CARTAGO: Estación El Sitio (KU 160207); $6.5 \mathrm{~km}$ ESE of Ojo de Agua, N. slope of Cerro Sákira, $3260 \mathrm{~m}$ (USNM 568678); Cerro Asunción, 11,000-11,100 ft (LSU 1264112650); Cerro de la Muerte, 3335 m (UMMZ 115403); N side summit, 
Pan American Highway (Cerro de la Muerte) (UMMZ 112000); Parque Nacional Chirripó (USNM 564368). LiMón: near base of Pico Blanco (=Cerro Kámuk), head of Río Lari, ca. $6000 \mathrm{ft}$ (USNM12236 - holotype); Río Teribe (=Río Tararia), Valle El Silencio, Río Cotón, $8000 \mathrm{ft}$ (USNM 539863). SAN José: Cerro Chirripó, Headwaters of Río Talari, 11,600 ft (LSU 12657-12664); Cerro de la Muerte, Hotel [La] Georgina, 3100 m (USNM 556131); Villa Mills, Cerro de la Muerte (USNM 569240); Cerro Buena Vista, near Cerro de la Muerte (MSB 28339); Cerro Estaquero, 10,000 ft (LSU 12640); La Piedra, ca. 4 mi SW Cerro Chirripó, 10,500 ft (LSU 12651-12656); Las Vueltas, $8000 \mathrm{ft}$ (UMMZ 62885); San Gerardo de Dota, ca. 2400-2700 m (KU 142690, 142691). PANAMA: BOCAS DEL TORO: Cerro Fabrega, $8400 \mathrm{ft}$ (USNM 539864); $17.5 \mathrm{~km}$ NNW of El Volcán, NE of Cerro Pando, $2180 \mathrm{~m}$ (USNM 516615, 516616). Chiriquí: Cerro Punta, Boquete Trail, $7600 \mathrm{ft}$ (USNM 322994-322996); 17 km NNW of El Volcán, head of Río Candela, 2000 m (USNM 516617).

C. merriami $(n=2)$-COSTA RICA (2): GUANACASTE: 4 to $5 \mathrm{~km} \mathrm{NE}$ of Tilarán (near Finca San Bosco, ca. 19.5 km SE Tilarán, between Quebrada San Bosco and Río Negro) (KU 84365). Puntarenas: Santa Elena, Monteverde Cloud Forest Reserve, Sendero Chomogo (MNCR 358).

C. monteverdensis $(n=1)$-COSTA RICA: Puntarenas: Monteverde, Monteverde Cloud Forest Reserve, "cloud forest at the continental divide," ca. $1550 \mathrm{~m}$ (KU 134852-holotype).

C. nigrescens $(n=122)$ - COSTA RICA: AlaJUELA: Monteverde Cloud Forest Reserve, 870-1840 m (KU 143371, 143377-143381, 159032-159037, 160216, 160217, 160219, 160979, 160980). PUNTARENAS: Monteverde, 1100-1790 m (FMNH 124101, 128415, 135224; KU 134898, 135008, 135083, 142053, 142054, 142689, 142786-142789, 143295-143297, 143382-143384, 143386-143396, 143496, 143636-143638, 144612, 157587-157594, 157597-157599, 157945, 157946, 157952, 158304-158306, 158631, 158980-158998, 160191-160198, 160218, 160948-160950, +4 uncataloged; LACM 67443, 64840, 67453; MMNH 14095; MNCR 352; UMMZ 115844, 115883, 115884, 117107-117110; USNM 568679, 568680, 570509); San Luis (ca. $2.5 \mathrm{~km} \mathrm{~S}$ Monteverde), $1200 \mathrm{~m}$ (KU 143385, 157595).

C. orophilus $(n=25)$ - COSTA RICA: AlaJUELA: $2 \mathrm{~km}$ oeste de Grecia (UCR 1298); Zarcero, $6000 \mathrm{ft}$ (FMNH 43974). CARTAGo: Cartago (BMNH 7.5.30.4, 95.8.17.6; KU 26932; UMMZ 66465, 67316); Guarco (KU 16563); Coliblanco (KU 26930, 26931); La Estrella de Cartago, 4500 ft (AMNH 14847, UMMZ 64147); Irazu Range (Volcán de Irazú) (AMNH 9640/9558-holotype). HeREDIA: Paso Llano, San José de la Montaña, 1800 m (KU 142692-142694); San Miguel de la Montaña, 1690-1700 m (KU 143372-143374); San Luis de Santo Domingo de Heredia, 1400 m (KU 143375, 143376). SAN José: Finca 2, Universidad de Costa Rica "Vargas Araya" campus (UCR 1500); El Muñeco, $10 \mathrm{mi}$ S of Cartago, $3800 \mathrm{ft}$ (UMMZ 67315); San Rafael de Montes de Oca, 4300 ft (KU 147100); Santa Ana (LSU 15753).

\section{References}

Allen JA (1895) Descriptions of new American mammals. Bull Am Mus Nat Hist 7:327-340

Anderson RP, Timm RM (2006) A new species of spiny pocket mouse (Rodentia: Heteromyidae: Heteromys) from northwestern Costa Rica. Am Mus Novit 3509:1-38

Bühler P (1964) Zur Gattungs-und Artbestimmung von NeomysSchädeln-gleichzeitig eine Einführung in die Methodik der optimalen Trennung zweier systematischer Einheiten mit Hilfe mehrerer Merkmale. Z Säugetierkd 29:65-93

Choate JR (1970) Systematics and zoogeography of Middle American shrews of the genus Cryptotis. Univ Kans Publ Mus Nat Hist 19: 195-317
Clark KL, Lawton RO, Butler PR (2000) The physical environment. In: Nadkarni NM, Wheelwright NT (eds) Monteverde: Ecology and Conservation of a Tropical Cloud Forest. Oxford University Press, New York, pp. 15-38

Fischer G (1814) Zoognosia tabulis synopticis illustrata. Volumen tertium. Nicolai Sergeidis Vsevolozsky, Mosquae

Guevara L, Cervantes FA (2014) Molecular systematics of small-eared shrews (Soricomorpha, Mammalia) within Cryptotis mexicanus species group from Mesoamérica. Acta Theriol 59:233-242

Haber WA (2000) Plants and vegetation. In: Nadkarni NM, Wheelwright NT (eds) Monteverde: Ecology and Conservation of a Tropical Cloud Forest. Oxford University Press, New York, pp. 39-94

He K, Woodman N, Boaglio S, Roberts M, Supekar S, Maldonado JE (2015) Molecular phylogeny supports repeated adaptation to burrowing within small-eared shrews genus of Cryptotis (Eulipotyphla, Soricidae). PLoS ONE. doi:10.1371/journal. pone.0140280 21 October 2015, 13 pp

Holdridge LR (1947) Determination of world plant formations from simple climatic data. Science 105:367-368

LaVal RK (2004) Impact of global warming and locally changing climate on tropical cloud forest bats. J Mammal 85:237-244

LaVal RK, Timm RM (2014) Apéndice 11: Mamíferos de Monteverde2014. In: Wheelwright NT, Nadkarni NM (eds) Monteverde: Ecología y Conservación de un Bosque Nuboso Tropical. Bowdoin Scholars' Bookshelf, Brunswick, Maine, Book 3, pp 853-863. https://issuu.com/bowdoinlibrary/docs/monteverde-part2 $/ 479$ ? $=11287169 / 10615867$. Accessed 5 August 2016

LaVal RK, Lawton RO, Timm RM (2016) The effect of environmental variables on nightly activity patterns of insectivorous bats monitored over ten years in a tropical premontane forest, Costa Rica. KU ScholarWorks, Lawrence [https://kuscholarworks.ku.edu/]

McDowell SB Jr (1958) The Greater Antillean insectivores. Bull Am Mus Nat Hist 115:113-214

Miller GS Jr (1911) Three new shrews of the genus Cryptotis. Proc Biol Soc Wash 24:221-223

Moreno CPA, Albuja VL (2014) Una nueva especie de musaraña del género Cryptotis Pomel 1848 (Mammalia: Soricomorpha: Soricidae) de Ecuador y estatus taxonomico de Cryptotis equatoris Thomas 1912. Papéis Avulsos de Zoologia 54:403-418

Nadkarni NM, Wheelwright NT (eds) (2000) Monteverde: Ecology and Conservation of a Tropical Cloud Forest. Oxford University Press, New York

Pine RH, Woodman N, Timm RM (2002) Rediscovery of Enders's smalleared shrew, Cryptotis endersi (Insectivora: Soricidae), with a redescription of the species. Mamm Biol 67:372-377

Pomel A (1848) Etudes sur les carnassiers insectivores (Extrait). Seconde partie.-Classification des insectivores. Arch Sci Phys Nat Genève 9:244-251

Pounds JA, Fogden MPL, Campbell JH (1999) Biological response to climate change on a tropical mountain. Nature 398:611-615

Quiroga-Carmona M (2013) Una nueva especie de musaraña del género Cryptotis (Soricomorpha: Soricidae) de la Serranía del Litoral en el norte de Venezuela. Mastozoología Neotropical 20:123-137

Quiroga-Carmona M, Molinari J (2012) Description of a new species of the genus Cryptotis (Mammalia: Soricomorpha: Soricidae) from the Sierra de Aroa, an isolated mountain range in northwestern Venezuela, with remarks on biogeography and conservation. Zootaxa 3441:1-20

Quiroga-Carmona M, Woodman N (2015) A new species of Cryptotis (Mammalia, Eulipotyphla, Soricidae) from the Sierra de Perijá, Colombia-Venezuela Andes. J Mammal 96:800-809

Reed CA (1951) Locomotion and appendicular anatomy in three soricoid insectivores. Am Midl Nat 45:513-671

Samuels JX, Van Valkenburgh B (2008) Skeletal indicators of locomotor adaptations in living and extinct rodents. J Morphol 269:1387-1411 
Sargis EJ (2002) Functional morphology of the forelimb of tupaiids (Mammalia, Scandentia) and its phylogenetic implications. J Morphol 253:10-42

Setzer HW (1950) Two new shrews of the genus Cryptotis from Panama. J Wash Acad Sci 40:299-300

Timm RM, LaVal RK (2000) Mammals. In: Nadkarni NM, Wheelwright NT (eds) Monteverde: Ecology and Conservation of a Tropical Cloud Forest. Oxford University Press, New York, pp. 223-244, $553-560$

Timm RM, LaVal RK (2016) Mammals of Monteverde-2000-2015. In: Wheelwright NT, Nadkarni NM (eds) Monteverde: Ecología y Conservación de un Bosque Nuboso Tropical. Bowdoin Scholars' Bookshelf, Brunswick, Maine, pp. 341-375, 843-863

Woodman N (2000) Cryptotis merriami Choate in Costa Rica: syntopy with Cryptotis nigrescens (Allen) and possible character displacement. Caribb J Sci 36:289-299

Woodman N (2015) Morphological variation among broad-clawed shrews (Mammalia: Eulipotyphla: Soricidae: Cryptotis) from highlands of western Honduras, with descriptions of three new cryptic species. Ann Carnegie Museum 83:95-119

Woodman N, Gaffney SA (2014) Can they dig it? Functional morphology and degrees of semifossoriality among some American shrews (Mammalia, Soricidae). J Morphol 275:745-759

Woodman N, Péfaur JE (2008 [2007]) Order Soricomorpha Gregory, 1910. In: Gardner AL (ed) Mammals of South America.
Marsupials, xenarthrans, shrews, and bats, volume I. University of Chicago Press, Chicago, pp 177-187

Woodman N, Stabile FA (2015) Functional skeletal morphology and its implications for locomotory behavior among three genera of mysoricine shrews (Eulipotyphla: Soricidae). J Morphol 276: $550-563$

Woodman N, Timm RM (1993) Intraspecific and interspecific variation in the Cryptotis nigrescens species complex of small-eared shrews (Insectivora: Soricidae), with the description of a new species from Colombia. Fieldiana Zool N Ser 74:1-30

Woodman N, Timm RM (1999) Geographic variation and evolutionary relationships among broad-clawed shrews of the Cryptotis goldmani-group (Insectivora: Soricidae). Fieldiana Zool N Ser 91: $1-35$

Woodman N, Cuartas-C CA, Delgado-V CA (2003) The humerus of Cryptotis colombiana and its bearing on the phylogenetic relationships of the species (Soricomorpha: Soricidae). J Mammal 84: 832-839

Woodman N, Matson JO, McCarthy TJ, Eckerlin RP, Bulmer W, Ordóñez-Garza N (2012) Distributional records of shrews (Mammalia, Soricomorpha) from northern Central America, with the first record of Sorex from Honduras. Ann Carnegie Museum 80:207-237 